\title{
CONSULTING DOMESTIC UNIVERSITIES IN USING A NEW EFFECTIVE TEACHING-LEARNING METHOD (KM-TFU) BASED ON THE METHOD OF 'TEACHING FOR UNDERSTANDING' AND THE CONCEPT OF 'LEARNING-BY-DOING KNOWLEDGE MANAGEMENT'
}

\author{
Marjan Chinnanpour \\ Student of Master of Business \\ Administration, Payam-e-Noor University- \\ Damavand Branch, Tehran, Iran
}

\begin{abstract}
Using the four modes of knowledge conversion (socialization, internalization, combination, and externalization) from Nonaka and Takeuchi 's theory of knowledge as an interplay between tacit and explicit knowledge, and applying these to the four key ideas of TfU (generative topics, understanding goals, performance of understanding, and ongoing assessment), a new method of teaching and learning is born, KM-TfU method. This paper is aimed at using this new effective teaching-learning method which is a more knowledge-based method of TfU using the concept of 'Learning-by-Doing Knowledge Management' and applying this method in open and distance learning (ODL) in domestic universities. This new method which is based on critical and creative thinking, reflection, dialogue, interaction, brainstorming and knowledge creation, exploration, and expansion can effectively be applied in open and distance learning to create a more dynamic global knowledge-based society.
\end{abstract}

Keywords: TfU, Learning-by-Doing Knowledge Management, KM-TfU, ODL

Increasing anomalies of the current educational system, high drop-out rates, low skill and knowledge levels among many students and low levels of student engagement in school or university courses, call for a major change. Educators understand that changes in student outcomes must be supported by parallel changes in curriculum and educational system. A new educational method, called the KM-TfU method designed in this paper can make this change happen. This method is an elaboration of the four key ideas of Teaching for Understanding (TfU) educational pedagogy with the four modes of knowledge conversion and three interrelated features of 'learning-by-doing' concept. Its learning outcomes are problem solving, critical analysis, higher-order thinking, and flexible understanding of academic subject matter by requiring teachers to be curious about students' ideas, to take delight in their thinking, and to encourage their creativity. Due to its flexibility, this method can be easily applied in open and distance learning.

This research was completed by taking into consideration the experimental results of practicing the TfU method in the medical school of Tehran University of Medical Sciences and the library studies which were carried out for further exploration. 


\section{TEACHING FOR UNDERSTANDING (TfU) EDUCATIONAL PEDAGOGY}

\section{What is TfU?}

'Teaching for Understanding' was a project zero based at the Harvard Graduate School of Education. Over a course of five years, members of this group talked together, developed curricula, tried them out in classroom, watched and talked with students, wrote case studies, and eventually solidified a framework that today identifies the central aspect of planning and teaching for understanding.

This collaborative thought and work of the teachers and researchers has formed a new educational pedagogy: Teaching for Understanding. This pedagogy uses the following four questions as a foundation for its framework: What topics are worth understanding? What about these topics needs to be understood? How can we foster understanding? How can we tell what students understand?

\section{Four Key Ideas of TfU}

The Teaching for Understanding framework includes four key ideas, based on the above four questions: generative topics, understanding goals, performances of understanding, and ongoing assessment. Clifford and Friesen (1993) define the four key ideas of TfU as follow:

Generative Topics: These topics of exploration have multiple connections to students' interests and experiences and can be learned in a wide variety of ways. They are central to the discipline, engaging to both students and teachers, and build on previous topics.

Understanding Goals: Statements or questions that express what is most important for students to understand during the period of a unit, a course (understanding goals), or over a long duration, such as a school year or semester.

Performances of Understanding: Activities that both develop and demonstrate students' understanding of the understanding goals by requiring them to use what they know in new ways.

Ongoing Assessment: The process by which students get continual feedback about their performances of understanding in order to improve them.

Teaching for Understanding method believes that the most important job of education is to provide students with knowledge that they can transfer in meaningful ways to other aspects of their present or future life. Thus, it prepares students to think critically and creatively and to explore understanding from an interactive perspective- one that asks the student to reflect on and share his own personal experiences because it's through reflection that one can assess his conclusions, actions and work processes to further his personal and professional development.

\section{Implementation of TfU in Educational Centers}

After the results offered by project zero at Harvard Graduate School of education, this pedagogy was practiced in many different schools, universities, educational institutes, websites and online learning centers. As an example, TfU was applied in the Medical School of Tehran University of Medical Sciences for teaching English courses for a period of four 
years by a group of English teachers and researchers, which I was a member of. Instead of learning Technical English from textbooks, students got active in projects which they were a part of. The method was applied for five different levels of English courses: Pre-English 1, Pre-English 2, General English, ESP1 (English for Special Purposes) and ESP2. Activities for each level were carefully designed based on the four key ideas of TfU to fulfill the needs of that level. Students engaged in interactive and goal-based activities with hospital patients, staff and other medical students to really feel the meaning of diseases, medical approaches, doctor-patient talk, and other medical concepts. Every semester, students had to work on a research project which they had to present in the Students Medical Conference at the end of the term. Since the conference was held by the students themselves, other than understanding the concepts of doing a research and presenting it, they also understood what a medical conference is all about and how they should manage it. Since the students' projects were on issues of their concern and they had to think critically and creatively in order to accomplish satisfactory results, the method was highly accepted and the results were extraordinary.

\section{Learning-by-Doing Knowledge Management}

Knowledge Management (KM) has been defined as the systematic and explicit management of knowledge-related activities, practices, programs and policies within the organization and aimed at supporting the enterprise's ultimate objectives (Wigg, 2000). Following Hansen (1999), the KM field can be mapped along two lines: managing explicit knowledge through Information Technologies, in the expert organization, and managing tacit knowledge through people, in the organization of experts. Jennex (2007) identifies tacit knowledge by contrasting respondents' practices with theoretical prescriptions for best practice in the field. In their seminal work, Nonaka and Takeuchi (1995) develop a theory of knowledge, describing the interplay between tacit and explicit along four modes of knowledge conversion:

Socialization (from tacit to tacit, from individual to individual): creating a shared space that is the basis for dialogue.

Internalization (from explicit to tacit, from organization to individual): creating identity and meaning.

Combination (from explicit to explicit, from group to organization): the process of systemizing concepts into a knowledge system, combining different bodies of explicit knowledge.

Externalization or explicitation (from tacit to explicit, from individual to group): Nanoka and Takeuchi (1995) define externalization as the process of articulating tacit knowledge into explicit knowledge triggered by dialogue and reflection. Amin and Cohendent (2004) discussed the idea that the externalization process "is a process of knowledge creation that alters both the codified and the tacit forms of knowledge". Boughzala and Ermine (2006) go beyond this definition and develop the idea that the process of explicitation itself co-creates both explicit and tacit knowledge.

Considering these four modes of knowledge conversion, Geisler (1999) describes a certain pragmatic approach to $\mathrm{KM}$ to harness the value of experience in the knowledge-driven firm and Boughzala and Ermine (2006) encapsulated this approach in the concept 
"Learning-by-doing", which means in fact three interrelated features:

Learning over time: being able to learn in action, being able to look back on the output knowledge initiatives, to make room for adjustments.

Learning together: being able to connect individual experiences through collective thinking. Learning from facts and from people through corporate cases and lessons learned.

\section{NEW PROPOSED METHOD, the KM-TfU Method}

All understandings are more or less idiosyncratic. This is in part due to differences in prior knowledge which learners bring to the situation (Newton, 2003). Considering this as the basis for designing a new educational pedagogy and taking in the four key ideas of TfU and the four modes and three features of learning-by-doing knowledge management, a more knowledge-based version of TfU method is formed, hereon called the KM-TfU Method. The first step of this method is a team work for teachers and students to design a curriculum with generative topics considering the students' concerns and in-depth understanding of how students think and learn. Students' prior knowledge, what he brings in to this team work, has the power to mediate curricula knowledge and determine how that student will make sense of the new information. This step builds up teachers' and Students' interaction and knowledge exchange in forming this curriculum and gives it identity based on the students' self-experiences and the knowledge which counts for the students.

Since Prior student knowledge can be identified only through dialogue, casual conversation, personal reflection and metacognition, the second step is to test the design of step one in practice by having dialogues, interacting and reflecting on this design in the classroom and making any necessary changes during the term, thinking of these changes as healthy actions not detrimental ones. What is actually being done is checking to see if the material covered in class is really the material that shall be covered, given these particular students and whether the teaching method is one that covers these students' way of thinking and learning. This is done through connections between teachers and students and between students and other students. This is a growing effort to engage students more deeply and thoughtfully in their own way of understanding the subject matters.

The third step is for students and teachers to share in class what they have learned from each other and how that has been useful in growing their understanding of that matter. Knowledge and skill in them do not guarantee understanding. As Vygotsky (1981) has mentioned, "it is through others that we develop into ourselves". It is the casual dynamics between the inter-and intra-generative processes of the me- and the we-experience in social interaction which makes these effects possible (Volosinov, 1973). Stary (2007) have called the process of learning through interaction 'reciprocal learning'- reciprocal relationship between two persons or groups. We may co-create ourselves within reciprocal relationship with the other. After going through the third step of the KM-TfU method, learning becomes a potentially non-linear phenomenon with multiplier effects as effects of self-reinforcing processes. This step is carried out as the students and teachers perform in a variety of thought-demanding ways with the topic in hand. In other words, they carry out a variety of "performances" concerning the topic-performance. These performances shall be designed in a creative way to take its audience beyond what they already know. 
The fourth and last step is for the teachers and students to provide feedback on their performances. Teachers can reflect on a student's performance, other students can reflect on a student's performance, the student can reflect on his own performance and students can students can reflect on the teacher's performance. This learning together technique acts as a checking tool to see whether the understandings were in the right track or not and if they were, how deep were they and where are the points which need to be strengthened.

This method designs a connected curriculum, extending generative knowledge-knowledge that connects. It also covers the all four ideas of TfU, all four modes of knowledge conversion and all three features of learning-by-doing knowledge management. It believes that each of us must "make meaning" or make sense of our own social world. Kinchloe and Steinberg (1993) put the social construction of reality into educational terms and say: The frontier where the information of the discipline intersects with the understandings and experiences that individuals carry with them to school is the point where knowledge is created (constructed). Thus, the truth of the courses is not what's found in the text books themselves, but it's rather the "truths" of personal experience that students and teachers bring to these texts. What students bring to expert knowledge will, in the end, inform how expert knowledge will be understood by students. Prior knowledge, what the student brings to the classroom, has the power to mediate school knowledge and determine how that student will make sense of new information.

\section{Application of the KM-TfU Method in ODL}

Since open and distance learning has the potential to generate new patterns of teaching and learning, and because it plays a special decisive role in the creation of the global knowledge-based society, this new method which covers the four key ideas of TfU and the features of Learning-by-doing knowledge management can be easily applied in it. All four steps of this method could easily be applied in ODL through websites, forums, weblogs, etc. This method avoids the downfall of much e-learning: linear, heavily text-based courses by offering more interactivity and taking into account what the student enjoys to learn on an ODL website. In contrast to the linear approach more common to e-learning, this approach keeps the student active at all times of his learning process. Other than the students and teachers having interaction, the designed pages on the websites are also interactive by providing links to select and activities to do and having the ability to be dynamically updated by new ways. This method plays a higher role of capacity-building and offers a more in-depth understanding of the subjects compared to the traditionally applied methods in ODL.

\section{CONCLUSION}

The new KM-TfU method provides students with an ability to think and act critically and creatively in a discipline by combining the four ideas of Teaching for Understanding pedagogy (generative topics, understanding goals, performances of understanding and ongoing assessment), the four modes of knowledge conversion (socialization, internalization, combination and externalization) and the three interrelated features of Learning-by-doing concept. Through this method, teaching and learning become more deliberate, focused, and reflective. Neither the students, nor the teachers feel that they are attempting to cover a hundred things, rather, they have a feeling that they are teaching and learning what is important and necessary for this society-the teacher and students of this certain course. Rather than handing knowledge down, teachers are helping students build up their own understanding. The result: Students understand. They are able to go beyond 
accumulating knowledge to applying it in novel and meaningful contexts, they have a better feeling about what they have learned since they were engaged in making it happen and they understand more deeply because they are aware that the teachers believe in their capacity to create, to construct knowledge and to assign meaning to what they have learned and experienced.

At last, it is suggested that domestic universities would take the advantage of applying the proposed method in their open and distance learning. The method presented in this research

May stimulate research in the related fields of educational pedagogy and its application in ODL.

\section{ACKNOWLEDGEMENT}

The author would like to thank her colleagues in the educational team practicing TfU at Tehran University of Medical Sciences for connecting with her and offering their reflection on her practice. Also, the valuable suggestion of Dr. Askarzadeh to encourage the author to prepare this paper is highly appreciated.

\section{REFERENCES}

Amin, A. \& Cohendet, P. (2004). Architectures of knowledge. Oxford University Press.

Boughzala, I. \& Ermine, J.L. (2006). Trends in enterprise knowledge management. London: ISTE Ltd.

Clifford, Patricia \& Friesen L. (Fall 1993). Teaching and practice. Harvard Educational Review, 339-358.

Hansen, M., Nohria, N., \& Tierney, T. (1999). What is your strategy for managing knowledge? Harvard Business Review, March-April, pp. 106-116.

Jennex, M.E. (2007). Knowledge management in modern organizations. Hershey: Idea Group Publishing.

Kinchloe, J.L. \& Steinberg, S.R. (Fall 1993). Tentative description of post-formal thinking: The critical confrontation with cognitive theory. Harvard Educational Review, 296-320.

Newton, D.P. (2003). Teaching for understanding: What it is and how to do it, NY: Taylor \& Francis e-Library.

Nonaka, I. \& Takeuichi, H. (1995). The knowledge-creating company. Boston: Harvard Business School Press.

Stary, C., Barachini, F., \& Hawamdeh, S. (2007). Knowledge management: Innovation, technology and cultures. Hackensack, NJ: World Scientific Publishing Co.

Volosinov, V.N. (1973). Marxism and the philosophy of language. New York: Seminar Press.

Wigg, K. (2000). Knowledge management: An emerging discipline rooted in a long history, in Despress D. 